\title{
ESTRATEGIAS COGNITIVO-CONDUCTUALES PARA INCENTIVAR LA CONCIENCIA MORAL RESPONSABLE EN LAS ORGANIZACIONES
}

\section{COGNITIVE STRATEGIES TO REINFORCE MORAL CONSCIOUSNESS AND PRACTICE IN ORGANIZATIONS}

\author{
Omar França-Tarragó \\ Universidad Católica del Uruguay, Uruguay
}

\begin{abstract}
Resumen: El artículo sistematiza algunos de los aportes que brinda la Psicología de enfoque cognitivoconductual, especialmente aplicables en el seno de las organizaciones, en orden a reforzar las actitudes y conductas éticamente responsables de los involucrados.

Se brinda especial atención a los factores que deben tenerse en cuenta, cada vez que se quiere contrarrestar o inhibir la tendencia deslizante de los contextos éticamente "laxos" de las organizaciones que, a su vez, deterioran la conciencia moral de los individuos y favorecen las conductas reprobables en la dinámica organizacional.
\end{abstract}

Palabras clave: Organizaciones, conciencia moral, ética organizacional, incentivos morales.

\begin{abstract}
This article systematizes the cognitive psychology perspective especially applied to organizations in order to reinforce moral responsibility in individual's attitudes and behaviors.

The author especially emphasizes the different components in the individual-organizations interaction that can be considered relevant for the inhibition of individual's unduly moral behavior and to neutralize the unethical organizational climate.
\end{abstract}

Keywords: Organizations, moral consciousness, organizational ethics, moral incentives.

\section{ESTRATEGIAS COGNITIVO CONDUC- TUALES PARA INCENTIVAR LA ETICA EN LAS ORGANIZACIONES}

¿Cuáles son los factores que favorecen la práctica de la ética en los miembros de la empresa? ¿Cómo hacer para que se vaya de "bien en mejor subiendo" y no, en una cuesta en bajada?

El más importante factor es, sin lugar a duda, la conciencia moral recta del individuo implicado puesto que, sin ella, no puede haber conducta correcta en ningún sentido.

El segundo factor es el contexto de las decisiones (las presiones y las oportunidades).

Los cursos de formación ética, los códigos de ética empresarial, los comités de ética, los supervisores de comportamiento ético, son diversos instrumentos que intentan brindar a los individuos elementos como para formar una conciencia moral recta y una predisposición a actuar de acuerdo con ella, contrarrestando las fuerzas negativas que puedan darse por las presiones + oportunidades.

Ahora bien, ¿cuales son los distintos componentes que intervienen en la mente de un individuo para que llegue a la decisión correcta y no a la conducta reprobable? ¿Cómo instrumentar una estrategia eficiente que revierta tendencias descendentes y se dinamice la excelencia ética?

¿Cómo instrumentar una estrategia eficiente para ir de bien en mejor subiendo y no en una cuesta descendente?

Con el propósito de describir los factores intervinientes y ayudar a pensar en estrategias que ayuden al mejoramiento de la conciencia moral y la toma de decisión correcta del individuo, contrarrestando la tentación al descenso ético en el ámbito de las organizaciones, exponemos lo que sigue. 


\section{TIPOS DE CONCIENCIA MORAL}

En todo proceso de crecimiento o mejoramiento de la conciencia moral intervienen dos dimensiones diferentes: la volitiva o motivacional por un lado y la cognitiva o informativa por el otro.

A) En los aspectos volitivos, los clásicos diferenciaban la conciencia moral entre recta y viciosa. La conciencia recta es la que tiene una disposición favorable (aspectos volitivos) a hacer lo bueno y evitar lo malo. Por el contrario, la conciencia viciosa es la que está predispuesta a hacer el mal.

A su vez, cabe ilustrar una cierta gradación en los componentes volitivos o motivacionales. En ese sentido puede diferenciarse una alta y baja motivación para obrar rectamente en orden a alcanzar las metas o ideales morales.

Motivación alta es la que no necesita estímulos exteriores, para actuar tal como el individuo entiende que debe hacerlo. Puede haber motivación "alta", tanto para obrar el mal como el bien. El calificativo de "alta" se refiere a que la motivación surge, fundamentalmente, de la voluntad interior del individuo, no porque alguien lo obligue desde fuera (las presiones $u$ oportunidades) ${ }^{1}$.

Motivación baja es la que, fundamentalmente, depende o es permeable a los estímulos o presiones exteriores. Estos estímulos pueden ser miedo a represalias, a perder recompensas económicas o sociales o a exponerse a la "sanción" social. Es decir, motivación "baja" es la de un individuo muy influenciable a las presiones sociales o a intereses de diverso tipo. Se dice que es motivación "baja" por cuanto si desaparecieran las presiones exteriores, el individuo no se dispondría a obrar en la línea de decisión que le indica la presión ejercida sobre él.

B) En sus aspectos cognitivos, los clásicos decían que la conciencia recta podía ser verdadera o errónea.

Conciencia recta verdadera sería aquella que sabe distinguir entre las conductas que ponen en práctica el bien y las que ponen en práctica el mal. Lo característico de este tipo de conciencia es que tenga un juicio moral determinado, producto de haber sopesado la suficiente información disponible respecto a los pros y contras de diversas alternativas, como para darse cuenta de la alternativa de acción correcta o la menos mala entre todas. Ejemplo, "debemos denunciar que en el Dpto $X$ de Aduana, se exige soborno"

Ahora bien, en algunos casos la conciencia recta, que busca la verdad moral, no llega a ella. En ese caso, su Juicio es indeterminado o indeciso. Si la conciencia, enfrentada a las diferentes alternativas de decisión experimenta que, con una misma acción se producen diferentes tipos de bienes y males, sin poder ver con claridad la conducta correcta que debe hacer en tal encrucijada, los clásicos hablaban de este tipo de situación como Conciencia perpleja. Ejemplo: "¿denunciamos ahora o esperamos un poco más?".

Conciencia recta errónea sería aquella que dispone de una información que es objetivamente falsa (pero no se da cuenta) y, por tanto, el individuo piensa (en base a la información que dispone) que un acto determinado es bueno pero, en realidad, es malo. Su error viene porque carece de información adecuada y suficiente; o la que tiene es falsa. Ejemplo, quema plásticos en su chimenea sin saber que eso desprende contaminantes altamente tóxicos para el ambiente.

La conciencia recta errónea no puede ser considerada culpable de lo que decide. Por el contrario, la conciencia viciosa siempre es culpable porque es consciente de que obra el mal y lo hace porque quiere hacerlo.

Ahora bien, entre el individuo de conciencia recta y el de conciencia viciosa se da un proceso de deterioro y paso de un tipo a otro, desde el menos involucrado al claramente culpable. Algunos autores (Zyglidopoulos, S. \& Fleming, $P, 2008$ ) describen 4 perfiles de individuos, según su involucramiento con la conducta reprobable:

1. El inocente colateral. Son miembros ordinarios de la organización que no participan en las actividades corruptas e ignoran que se lleven a cabo.

2. Los participantes que se excusan. Estos 
hacen actos supuestamente neutrales, gracias a los cuales se perpetúa la corrupción. Estos individuos son testigos del delito que ejecutan otros, pero no hacen nada para impedir que se perpetúe.

3. Los cómplices racionalizadores. Serían los que participan en la conducta corrupta porque son mandados a hacerlo; posteriormente, racionalizan su participación como "obediencia debida": "hago lo que me mandan".

4. Los perpetradores culpables. Ellos son los plenamente conscientes de que ponen en práctica actos reprobables.

\section{PROCESO DE DECISION MORAL}

Hay un conocido modelo de 4 pasos para la decisión moral (Wasieleski, D. \& Hayibor, S., 2008) que ha sido formulado de la siguiente manera: $1^{\circ}$. Reconocimiento de la identidad del acto o de la conducta como "moral": el individuo logra percibir que una conducta determinada implica un dilema de naturaleza moral o, por el contrario, sólo le atribuye al acto una naturaleza de tipo técnico-procedimental o administrativa. Este reconocimiento depende de los componentes que, en seguida, describiremos.

$2^{\circ}$. El juicio moral. Ante un hecho que el individuo reconoce como teniendo una naturaleza de tipo moral, toma posición evaluativa y afirma: debo hacer "esto", o lo otro.

$3^{\circ}$. Intención moral. Habiendo juzgado lo que debe hacer, el individuo se dispone a ejecutarlo. En este nivel intervienen las presiones del ambiente o las oportunidades negativas que pueden contrarrestar su disposición moral recta.

Tabla 1.

\begin{tabular}{|c|c|c|}
\hline \multicolumn{3}{|c|}{$\begin{array}{l}\text { CUATRO TIPOS DE CONCIENCIA MORAL (GERA, A. 2006) } \\
\text { CUATRO ESTRATEGIAS PARA CORREGIRLAS O MEJORARLAS }\end{array}$} \\
\hline $\begin{array}{l}\text { Nivel de motivación } \\
\text { moral }\end{array}$ & $\begin{array}{l}\text { INDETERMINADA (incierta o insuficientemente } \\
\text { informada) }\end{array}$ & DETERMINADA (verdadera, o correctamente informada) \\
\hline $\begin{array}{l}\text { Rectitud } \\
\text { ALTA }\end{array}$ & $\begin{array}{l}\text { PERPLEJIDAD O INCERTIDUMBRE DILE- } \\
\text { MÁTICA } \\
\text { El individuo no dispone de suficiente información } \\
\text { para llegar a darse cuenta cual es la alternativa } \\
\text { más correcta de entre varias. Ej. El individuo si- } \\
\text { gue preguntándose ¿Debemos denunciar o no? } \\
\text { Estrategia 1: proporcionar la información sufi- } \\
\text { ciente y adecuada para que individuo llegue a } \\
\text { darse cuenta de la salida correcta }\end{array}$ & $\begin{array}{l}\text { INTENCIÓN CIERTA Y RECTA } \\
\text { Ej. Ej. juzga y dice: "debemos denunciar", o por el contra- } \\
\text { rio, "no debemos denunciar" } \\
\text { Estrategia 2: agregar más información para que el indivi- } \\
\text { duo corrobore que su decisión moral fue correcta, a fin de } \\
\text { que pueda mantener elevada la motivación recta }\end{array}$ \\
\hline Rectitud baja & $\begin{array}{l}\text { CONCIENCIA LAXA } \\
\text { Ej. "y bueno.... no pasa nada si no denunciamos. } \\
\text { Todos hacen lo mismo" } \\
\text { "más adelante veremos" } \\
\text { "reunamos una comisión...." } \\
\text { Estrategia 3: debe ayudársele a vencer miedos, } \\
\text { vergüenzas u otros estímulos negativos; debe } \\
\text { asegurársele al individuo que su buena acción } \\
\underline{\text { será recompensada }}\end{array}$ & $\begin{array}{l}\text { DISCULPA RACIONALIZADORA } \\
\text { AUTOJUSTIFICACIÓN } \\
\text { EI EI individuo racionaliza sobre los motivos de por qué } \\
\text { no se toma la decisión recta. También puede ponerle } \\
\text { eufemismos a una acción notoriamente mala. } \\
\text { Ej. "no denunciamos porque podríamos quedar mal } \\
\text { ante...." } \\
\text { "no denunciamos sino que informamos a las autoridades de } \\
\text { lo que observamos" } \\
\text { Estrategia 4: debe darse certeza a los individuos que el } \\
\text { delito será castigado severamente, y que hay mecanismos } \\
\text { eficaces para descubrir el delito. Debe combatirse mitos } \\
\text { organizacionales tales como "todos hacen lo mismo", "si lo } \\
\text { haces nadie te descubre" }\end{array}$ \\
\hline
\end{tabular}


$4^{\circ}$. Comportamiento moral: el individuo ejecuta lo que considera recto. Este comportamiento depende, a su vez, de las características del individuo, del contexto, y de las características del acto moral en sí mismo.

\section{La percepción del acto como "moral" y el juicio subjetivo del decisor}

Los pasos 1 y 2 son de decisiva importancia.

Se han descrito 6 componentes que influyen en la percepción que el individuo tiene de la intensidad o naturaleza moral del acto y de su propio deber respecto a la conducta a tomar. Esos seis componentes serían los siguientes Wasieleski, D. \& Hayibor, S., 2008):

La magnitud de las consecuencias. Esto significa la percepción que tiene el individuo del conjunto o suma de beneficios y perjuicios que pueden resultan del acto en cuestión y afectar a personas o instituciones.

El consenso social. Se refiere a la percepción que tiene el individuo respecto a si el grupo en el que se encuentra el decisor, tiene "motivos" para valorar tal acto como "bueno" o "malo".

Los motivos pueden ser individualistas: la maximización de los intereses financieros, de prestigio, o de poder que tiene cada uno.
Motivos colectivistas: los intereses del conjunto de la organización.

Motivos corporativistas: los intereses grupales o gremiales al que pertenece quien toma la decisión.

Proximidad. Se refiere a cuan próximo (física, psicológica o socialmente) se encuentra el agente respecto a los perjudicados o beneficiarios del acto.

Probabilidad del efecto. Es la percepción que tiene el individuo respecto a la probabilidad de que el acto realmente ocurra y provoque las presumibles consecuencias.

Inmediatez temporal. Se refiere a la percepción del tiempo que transcurrirá entre la ejecución del acto hasta que se produzcan las consecuencias esperadas de la conducta en cuestión. Concentración del efecto. Se refiere al número de personas afectadas por el acto (cuanto menos personas, más concentrado).

\section{El paso a la acción moral}

El último paso, la ejecución del acto moral, ha sido muy estudiado. Se han señalado dos modelos diferentes (MacLean, 2008), que explicarían por qué el individuo pasa a hacer o no hacer una conducta reprobable.

Por un lado estaría el modelo tradicional o racionalista.

Gráfico 1.

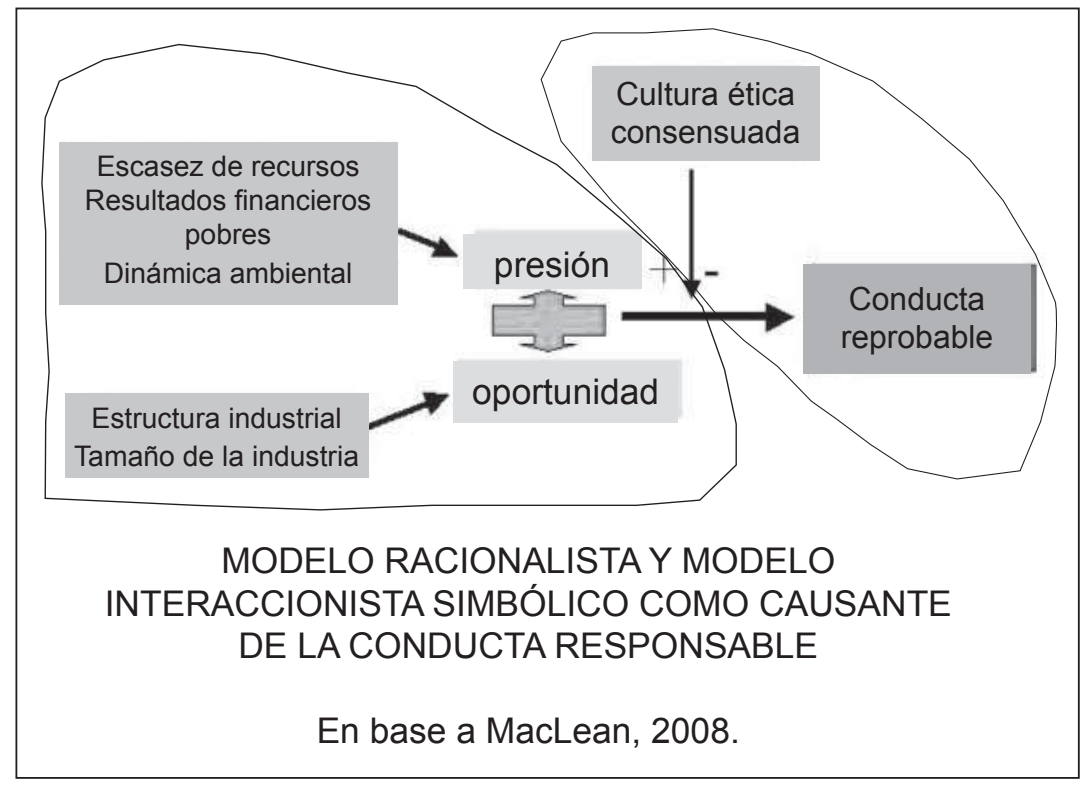


Según quienes lo sostienen se considera que la suma de la "presión" sobre la organización o sobre el individuo, más la "oportunidad" de poder hacer la mala conducta, es lo que explica el paso a la acción.

La "presión" es experimentada por la organización cuando ésta se encuentra con escasez de recursos disponibles para llevar a cabo sus metas, o cuando sus resultados financieros han sido insuficientes.

Oportunidad es el contexto o el ambiente que hace posible la corrupción. La "oportunidad", a su vez, está dada por la estructura de la industria y el tamaño de la organización. Lo decisivo de la oportunidad es la previsión del individuo que puede evitar ser visto y castigado Ambas cosas permiten que la acción pueda llevarse a cabo en el momento en que surge la oportunidad.

Según este modelo, lo decisivo para la ejecución de la conducta moral correcta o reprobable es el cálculo racional que hacen los individuos que dirigen la organización al sopesar las consecuencias de sus actos.

En el modelo racionalista, la estrategia gerencial deberá ser evitar el exceso de presión y lograr controlar las oportunidades que puedan presentarse para llevar a cabo la conducta corrupta. Para este modelo racionalista, el castigo de faltas y la prevención de las ocasiones sería lo decisivo para inhibir la conducta reprobable.

\section{Insuficiencia del modelo racionalista}

Según MacLean (2008) el modelo racionalista tradicional es incompleto y ella lo complementa por el que llama modelo interaccionista simbólico. Según este modelo, los "marcos" cognitivos son de decisiva importancia para interpretar los hechos como buenos o malos. Son como focos que iluminan el cuadro y ponen de relevancia un hecho, dejando en la penumbra a otros. Los "marcos" cognitivos son constructos sociales que -siguiendo a la autora- se consideran válidos por los grupos sociales en los que acontece la conducta en cuestión.

En ese sentido, si calificamos a una conducta como "desafío", es muy diferente a si la calificamos como "oportunidad". Si la calificamos como "amenaza" reaccionaremos ante ella con mucho menos creatividad (seremos más conservadores), que si la calificamos como oportunidad. Los marcos cognitivos sociales de una organización se decantan y sedimentan como "cultura" organizacional. Esta tiene ciertos símbolos, ciertos rituales, ciertas palabras y eslóganes que son validados socialmente, no precisamente por cálculos racionales (primer modelo).

En este modelo, se supone que lo decisivo no es el cálculo racional sino dar por supuesto como válidas las conductas consideradas "normales" en un contexto social determinado.

Para el modelo simbólico, por más que haya presión y oportunidad para el individuo o la organización, si la conducta no es enmarcada como "normal" o "aceptable" por el grupo social en el que se inserta, no se Ileva a la práctica. El cálculo racional, "solo", no sería suficiente para que se pase a la acción reprobable. Se necesita la validación del "consenso" social.

En este modelo, lo principal es el simbolismo social que adquieren las conductas. La "Cultura" organizacional es lo decisivo para que un individuo se sienta motivado a ejecutar determinada conducta. Y la tarea de construir tal cultura del consenso y la validación social es de primer orden para los gerentes, si quieren que los individuos se inhiban frente a determinadas conductas y se sientan movidos a ejecutar otras.

\section{FACTORES QUE FAVORECEN LA CON- DUCTA REPROBABLE}

\section{Las justificaciones o racionalizaciones}

El componente cognitivo más influyente, dentro de lo que se ha descrito como el triángulo perverso ${ }^{2}$ del paso a la acción, es el de la justificación.

Esta operación cognitiva o simbólica es la que valora el acto corrupto como "deseable" o, en otras palabras, inhibe su calificación como acto "malo". 
En ese sentido, es interesante recoger aquí los aportes de los estudiosos de la mentalidad criminal. Algunas de las justificaciones que utilizan los criminales para justificar sus delitos, nos proporcionan alguna luz para entender las justificaciones que usan quienes están predispuestos a llevar a cabo la conducta éticamente reprobable. Según ellos, el criminal suele utilizar como justificación de lo que ha hecho o de lo que estaría dispuesto a seguir haciendo, algunas de las "razones" siguientes:

- el criminal niega tener responsabilidad legal, o aduce que la ley no se aplica a su caso, o la ley no incluye la falta de que lo acusan,

- el criminal niega haber hecho un daño real,

- el criminal niega la existencia de la víctima,

- el criminal condena a quienes lo acusan,

- el criminal apela a lealtades mayores: "todos lo hacen", "lo contrario sería quedar en ridículo", "hice lo que me permitían las circunstancias", "no me quedó más remedio", "yo obedecía órdenes",

- el criminal niega haber tenido conciencia de la falta,

- el criminal reivindica tener un derecho exclusivo a hacer el comportamiento desviado (ej., matar a la mujer al verla con el amante, o "para poder exportar hay que pagar "coimas").

Siempre es motivo de admiración el saber que individuos aparentemente "correctos" llegan a perpetrar actos sorprendentemente antisociales. Para que un individuo "normal" (como los gerentes de Enron y World Com, o Madoff) se vuelvan corruptos o criminales, tiene que darse en su mente un proceso de transformación suficientemente profundo del juicio moral, para llegar a tal extremo.

Lo primero que señalan los autores es que ha de pasarse por la banalización de la corrupción, a fin de que tal conducta se vuelva "normal". La banalización necesita de la racionalización como imprescindible condición para ablandar el terreno. Las racionalizaciones son estrategias mentales que justifican las actividades corruptas, tanto retrospectiva como prospectivamente. Cuanto más pode- rosas sean, más se sentirá movido el individuo a llevar a cabo la falta ética.

Estas racionalizaciones pueden tener su fundamento tanto en la mentalidad de los individuos, como en la misma organización y su clima ético maquiavelístico, muchas veces expresado en un lenguaje eufemístico. Hay un continuo de racionalización cognitiva en la mente de los sujetos hasta que, finalmente, termina en individuos corruptos, ladrones, torturadores $o$ asesinos.

En el caso de los torturadores el proceso de involucramiento de los individuos en la conducta delictiva ha sido descrita así:

1er paso: la integración del posible torturador en una organización despersonalizada, con una cadena clara de mando y una ritualidad de obediencia,

$2^{\circ}$ paso: la ubicación del posible torturador en un "ambiente de criminalidad", o muy cercano a éste, donde suele practicarse la tortura (lugares donde se les hace pasar hambre, o se les somete a humillaciones físicas, tales como plantones, etc),

3er paso: cruce de la línea. Al posible torturador se lo involucra dándole órdenes "aisladas" de cometer un acto criminal. El candidato a torturador se va "acostumbrando"

$4^{\circ}$ paso: la reiteración frecuente de las conductas de tortura y la rutinización de dicho comportamiento. trabajo.

\section{La distancia ética como factor favorecedor de la conducta reprobable}

¿Cómo se pasa de ser "inocente colateral" a "inocente participante"; y de éste, a "activo racionalizador" hasta llegar a ser "perpetrador culpable"? (Zyglidopoulos, S. \& Fleming, P., 2008).

Tradicionalmente se ha dicho que, el paso de uno a otro perfil de individuo depende de la socialización y de factores institucionales (presiones y oportunidades), que ayudan al proceso de racionalización o justificación de los actores.

Pero otro factor que se ha visto de gran importancia es la "distancia ética", entre la de- 
cisión corrupta y las consecuencias prácticas de esta decisión.

Sería la distancia ética la que facilita la transición desde ser un "inocente colateral" pasando por ser un "racionalizador", hasta llegar a ser un "perpetrador culpable". En ese sentido, a mayor distancia entre un acto o decisión corrupta y sus consecuencias favorables para quien decide, (o desfavorables para el "otro" perjudicado) más fácil será para los individuos dentro de una organización, tolerar, justificar o ejecutar las decisiones o actos corruptos.

Tratamos de esquematizar en el Gráfico 2 la interacción de dos dinamismos contrarios en la interna de una organización. Indicamos algunos factores que contribuyen al "declive" ético, así como algunas estrategias que pueden diseñarse para contrarrestarlo. En el esquema se indica con líneas y flechas descendentes, los factores favorecedores (+) del declive. Por el contrario, se indican con líneas y flechas ascendentes a las estrategias positivas $(+)$ tendentes a revertir el declive. El área cada vez más pequeña de los semicírculos y el grosor cada vez menor de las flechas descendentes presuponen que, quienes optan por la conducta viciosa o culpable, son una minoría en relación al conjunto de los colaterales no corruptos.
Lo mismo quiere indicarse con el grosor progresivamente mayor de las flechas ascendentes, siempre y cuando las estrategias antideclive, que serán motivo del próximo numeral, se pongan en práctica y funcionen como se esperan.

Según los autores que estamos siguiendo hay dos tipos de distancia ética: la temporal y la estructural:

La temporal se refiere a cuan lejos en el tiempo se producirá la consecuencia de una decisión o de un acto corrupto. También tiene que ver con el cortoplacismo y largoplacismo de los efectos de nuestras decisiones.

La estructural. Tiene que ver con la especialización y separación del individuo, respecto a las consecuencias de sus actos, así como con la departamentalización y fragmentación estructural de la organización.

Una vez que el individuo asume el rol de "participante inocente" -o cualquiera de los siguientes perfiles- la mayor distancia (temporal) entre el acto corrupto y sus consecuencias favorables para quien decide, puede facilitar su transición a la próxima etapa, por ejemplo, pasar a ser "activo racionalizador".

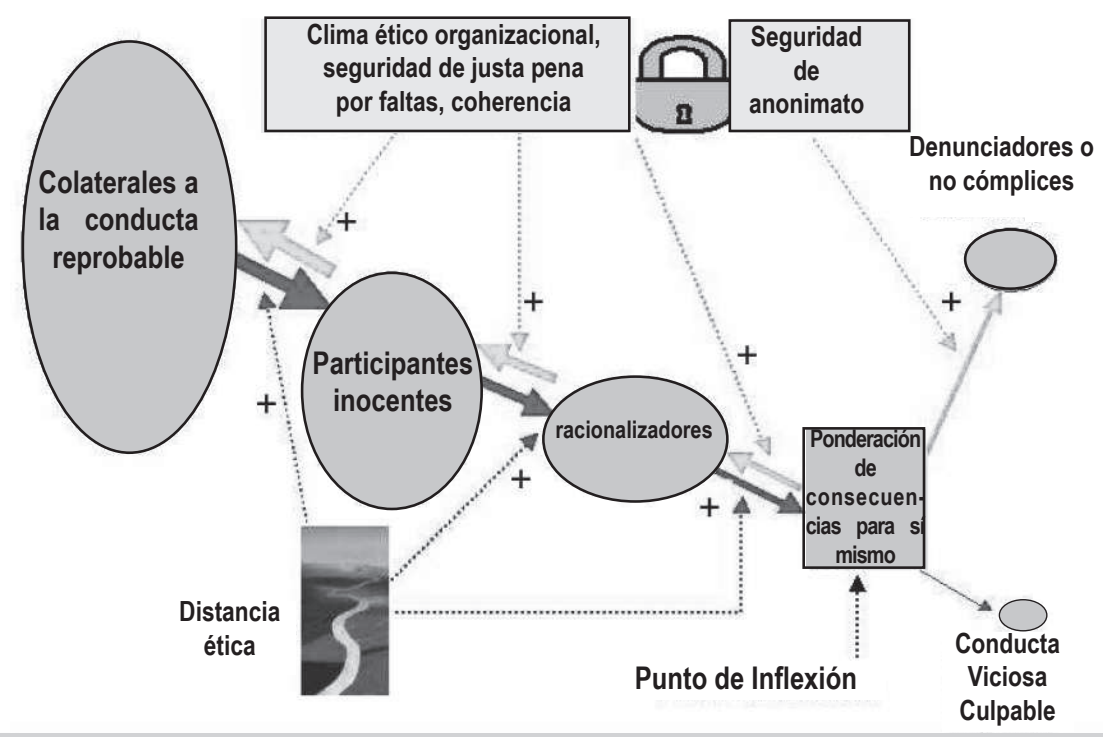

DINÁMICA DE RECHAZO/TOLERANCIA A LA CONDUCTA INMORAL O REPROBABLE EN UNA ORGANIZACIÓN

Gráfico 2. Inspirado en Zyglidopoulos 2008, modificado por Omar França 2009 
Eso es porque el individuo "no ve", en el corto plazo, las consecuencias negativas para los posibles damnificados, que podrían surgir de la puesta en práctica de sus decisiones o actos corruptos. Y a la inversa: si la decisión corrupta puede causar, en un corto período de tiempo, un efecto perjudicial para el que decide, más se sentirá inhibido el individuo corrupto, a tomar tal decisión.

El individuo tiende a racionalizar que la corrupción le va a traer una ventaja inmediata y que el posible castigo puede venir a muy largo plazo. Hay una tendencia a pensar que lo relevante son las consecuencias inmediatas y no las del largo plazo. De ahí que el racionalizador tiende a darle importancia a estas consecuencias inmediatas sobre las otras.

1. En cuanto a la distancia estructural, el primer aspecto a subrayar es que el individuo racionalizador le da más relevancia a las consecuencias ventajosas para sí mismo, y no para los terceros inocentes. En una organización, las consecuencias desventajosas de una decisión o acto corrupto suelen estar más frecuentemente relacionadas con "los extraños" o "anónimos" perjudicados ${ }^{3}$. En cambio, las consecuencias ventajosas para el corrupto que decide, suelen ser visibles y palpables, es decir, suelen redundar en beneficio del individuo racionalizador. Si el lugar que ocupo en la organización, me permite visualizar los efectos concretos del acto corrupto, y las consecuencias "molestas" que eso puede acarrear sobre mi gestión, tenderé a refrenarme. Por ej., si soy gerente general y voy a recibir, permanentemente, las quejas de los consumidores por el defecto de diseño de un automóvil, me refreno en la decisión de continuar con el diseño fallado.

2. En otro sentido, la distancia estructural incrementa la propensión a la racionalización cuando el individuo se ve a sí mismo como una "mínima" parte de un todo "inmenso". Si se está en una institución corrupta, donde el individuo percibe que "todos lo hacen", tenderá a justificar su "pequeña" corrupción, atribuyéndola a la influencia de la "gran" corupción del ambiente. Con esta distancia es más fácil que un funcionario piense que su comportamiento moral corrupto no es grave $y$, en consecuencia, justifica que no contribuye "sustancialmente" a la corrupción de la organización. Los actores tienden a ver su rol "individual" como insignificante en el "todo". Por ej. en World Com se sabía que la compañía estaba en problemas; pero la compartimentalización estructural hacía que el engaño fuera menos alarmante para los racionalizadores. La fragmentación y la complejidad de la especialización, llevaba a pensar que el fraude fuese menos "pesado" de lo que en realidad era. A esta forma de "distancia estructural" también se ha dado en llamar el aislamiento burocrático.

3. Otro aspecto de la distancia estructural, es que los individuos tenderán a justificar más su comportamiento corrupto si juzgan que "sólo" les corresponde hacer una "partecita pequeña" de la "totalidad" del acto malo o de la decisión corrupta.

\section{ALGUNAS ESTRATEGIAS PARA LA MO- RALIZACION POSITIVA EN LAS ORGANIZACIONES}

Después de todos los elementos analíticos que hemos desarrollado hasta ahora, ¿qué estrategias podrían instrumentarse para mejorar la práctica de la ética en la empresa?

Las presiones y las oportunidades, en la medida que son factores importantes en la decisión reprobable, deben ser desveladas permanentemente ${ }^{4}$. Esto significa que, cuanto más públicas se hagan las presiones y las oportunidades, menos se intentará hacer la conducta reprobable ${ }^{5}$.

Los elementos simbólicos o la valoración social que "ablanda" el delito o la falta, es decir, las justificaciones frecuentemente asumidas como válidas por los "colegas", son de fundamental importancia. En consecuencia, una calificación clara y decidida a nivel institucional sobre lo que es considerado una conducta "prohibida", diferenciándola de una "permitida" y una "obligatoria", es principalísima para sistematizar una "cultura ética empresarial" que disminuya las racionalizaciones contrarias a dicha calificación. 
El combate implacable a los mitos cognitivos de los racionalizadores es de decisiva importancia. Los "mitos" corruptógenos son, entre otros, los siguientes: "eso todos lo hacen", "si no lo haces, quedas en ridículo", "así son los negocios", "no puedes cambiar lo que siempre fue igual", "si quieres competir no te queda más remedio que...." "para lograr lo que te propones hay que buscar medios que resulten", "yo tengo que acatar órdenes..", "una cosa son los papeles, pero la realidad es otra". El maquiavelismo o el clima ético empresarial del tipo espontaneísta vitalista (en el que cualquier medio se justifica por el fin que se quiere lograr), es el caldo típico de los mitos corruptógenos.

La racionalización está en estrecha relación con la distancia ética entre la falta y sus consecuencias (que suelen ser favorables al corrupto y desfavorables para terceros inocentes). Cuanto más se acorte dicha distancia, en el tiempo y en el espacio, más se inhibirá la conducta reprobable. Por el contrario, cuanto más se fragmenten las decisiones (distancia ética estructural); cuanto más tempranas sean éstas y tardías las consecuencias (distancia ética temporal) más se favorecerá la conducta reprobable. Si el racionalizador está en una corta distancia ética y es capaz de percibir las graves consecuencias negativas que tendrá para él caer en la conducta corrupta, y ve que no superan a las posibles ventajas de la conducta honesta, tenderá a volverse denunciador del delito, en lugar de ser un perpetrador culpable (ver ángulo inferior derecho del cuadro).

1. Lo hará más fácilmente si encuentra que su anonimato en la denuncia, está garantizado por la organización, es decir, que no "sufrirá" consecuencias por las represalias de sus pares corruptos. Cuanto menores sean las consecuencias negativas de denunciar, más será la probabilidad que el individuo pase a ser denunciador del delito, y no perpetrador culpable.

2. Si el individuo tiene una alta motivación para la acción ética, lo fundamental es proporcionarle buena información al respecto. En cambio, los individuos de baja motivación son inhibidos en la inconducta moral si se les pone delante de su mente la seguridad de alternativas amenazantes y "dolorosas" en caso de seguir la conducta mala.

3. El clima ético organizacional de tipo deontológico (aquel que se basa en la defensa de la dignidad de las personas, principios y normas universales) y la consistencia de esos valores con la "cultura" ética organizacional y las decisiones concretas, son fundamentales para contrarrestar la cuesta en bajada. Forma parte del clima ético, la seguridad de la justa pena a las conductas contrarias a los valores éticos asumidos como propios por la empresa. Especialmente relevante son aquellas señales organizativas en las que todos los involucrados saben que en la empresa se "hace lo que se dice que se hace".

\section{REFERENCIAS}

Aguilera,R., Vadera,A. (2008). The dark side of authority: antecedents, mechanisms and outcomes of organizational corruption. Journal of Business Ethics 77: 431-449.

Geva, A. (2006). A typology of moral problems in Business: a Framework for ethical management. Journal of Business Ethics 69: 133-147.

Lowney, C. (2008). El liderazgo al estilo de los jesuitas: las mejores prácticas de una compañía de 450 años que cambió el mundo. Bogotá: Norma.

MacLean, T. (2008). Framing an organizational misconduct: a symbolic interactionist Study. Journal of Business Ethics 78: 3-16.

Vadera, A. (2008). The dark side of authority: antecedents, mechanisms and outcomes of organizational corruption. Journal of Business Ethics 77: 431-449.

Wasieleski, D., Hayibor, S. (2008). Breaking the rules: examining the facilitation effects of moral intensity. Characteristics on the recognition of rule violation. Journal of Business Ethics 78: 275-289.

Zyglidopoulos, S., Fleming, P. (2008). Ethical distance in concept firms: why do innocent bystanders become guilty perpetrators. Journal of Business Ethics 78: 265-274. 


\section{Notas}

1 En un reciente libro publicado sobre el liderazgo al estilo de los jesuitas, el autor desarrolla que una pieza clave en el liderazgo religioso que tuvo la orden religiosa "Compañía de Jesús" fundada por san Ignacio de Loyola es que sus miembros no necesitan controles externos para tener una motivación firme y continua a la hora de llevar a cabo sus difíciles misiones en países donde los occidentales nunca habían llegado antes. (Lowney, C. 2008).

2 El triángulo estaría integrado por las presiones, las oportunidades y las justificaciones. (Aguilera, R., Vadera, A. 2008).

3 Los menos de 5.000 muertos en las torres gemelas han causado "horror" en el mundo. Sin embargo, los 16.000 muertos de hambre que se producen cada día en el mundo, son "anónimos", "lejanos", "extraños". No impactan nuestra sensibilidad. Respecto a los que mueren de hambre tenemos una gran distancia ética. Con respecto a los muertos en las torres gemelas de Nueva York, tenemos una "corta" distancia ética.
4 San Ignacio de Loyola en sus reglas de discernimiento espiritual recomienda que el individuo que se siente tentado a hacer algo malo debe hacer lo contrario a lo que busca un "vano enamorado". Según San Ignacio, un vano enamorado sería el que trata de seducir a una mujer casada pero sin que su esposo sepa que anda merodeando a la esposa. Apenas se entera que el marido sabe de su presencia o que la esposa le dice que el individuo la está visitando, el vano enamorado desaparece.

5 Un ejemplo de otro campo muy distinto, la práctica médica, nos muestra cuán importante es la visibilidad de la conducta que se quiere llevar a cabo. Si una mujer viene a la consulta médica diciendo que está embarazada y quiere abortar y se le muestra con imágenes el estado actual del embrión o del feto, es altamente probable que la mujer opte por no abortar. Cognitivamente, es característico de un gran número de mujeres que quieren abortar que tengan una imagen muy "borrosa" de la realidad que se da en su vientre (es un "coágulo", un "conjunto de células", "una especie de quiste del útero", etc.). Algo parecido pasa en la comunicación vía internet. Es mucho más fácil que se agreda a otros internautas -vía correo electrónico o en los blogs- que en el trato personalizado personal. 